Marcel P. Pauluk , André L. Battaiola [UFPR]

\title{
Aspectos do design da informação de um software semiótico
}

\author{
Information design aspects of a semiotic software
}

\begin{abstract}
semiótica, design da informação, software
SignType - Tipificador Semiótico Assistido para Dados Fenomenológicos - propõe-se como um software simultaneamente didático e aplicável. Seus principais objetivos são: (1) capacitação científica de pesquisadores e estudiosos de quaisquer áreas do conhecimento na metodologia de classificação semiótica de extração peirceana; e (2) conversão de input fenomenológico (descrições impressionísticas) em output semiótico (tipos de signo), otimizando o aproveitamento do potencial científico da semiótica pelo usuário. Parte do esforço destinado a esta otimização vem do projeto de design da informação desenvolvido para o aplicativo. Neste artigo são analisados modelos gráficos que buscam representar conceitos e outros aspectos teóricos da semiótica de Charles S. Peirce cujas principais características são sua configurabilidade (permitem que certas informações sejam ou não visualizadas segundo critérios hierárquicos variáveis), alternabilidade (substituíveis por modelos diversos) e modularização (que facilitam a comparação entre as classificações em curso).
\end{abstract}

semiotics, information design, software

SignType - Assisted Semiotic Typifier for Phenomenological Data - is a simultaneously didactic and applicable software. Its mains goals are: (1) scientific capacitation of researchers and scholars from various knowledge areas on the methodology of Peircean semiotic classification; and (2) transformation of phenomenological input (impressionistic descriptions) into semiotic output (kinds of sign), optimizing the use of the scientific potential of semiotics by the user. Part of the work carried on this optimization comes from the information design project developed for this application. In this paper, graphic models that aims to represent concepts and other theoretical aspects of Charles S. Peirce's semiotics are analysed. Their key characteristics are customizability (permits certain information to be seen or not under diverse hierarchy criteria), alterability (being interchangeable for other models) and modularization (making comparisons between ongoing classifications easier).

\section{Introdução}

É constatável, entre as diversas áreas do conhecimento científico, um generalizado interesse pelo potencial da semiótica aplicada, em especial daquela fundada na obra do filósofo e polímata norteamericano Charles S. Peirce (1839-1914). Uma pesquisa envolvendo qualquer uma das principais palavras-chave relacionadas ao estudo de processos representacionais - signo(s), Peirce, semiótica(o)(os)(as), semiose, semiologia, símbolo(s),semiológico(a)(os)(as), sígnico(a)(os)(as), representação(ões) - realizada em 06/12/2003 na base corrente do diretório de grupos de pesquisa cadastrados na plataforma Lattes revelou 553 grupos distribuídos entre 40 diferentes áreas do conhecimento (com proeminência das ciências humanas e sociais).

Apesar deste interesse multíplice, grande parte dos pesquisadores envolvidos não está metodologicamente capacitados para explorar com eficácia os conceitos instrumentais desta disciplina (Santaella, 2002, pp. xi-xvii); Como conseqüência disto, os resultados de pesquisas nas quais a compreensão de processos sígnicos faz-se necessária muitas vezes têm ficado aquém das capacidades heurística, elucidativa e crítica da semiótica.

Por ser uma ciência de insigne caráter transdisciplinar (Nöth, 1995, p. 125), a semiótica necessita ser retroalimentada com os resultados de sua aplicação e de sua efetiva interação com outras ciências. Resultados incorretos ou insatisfatórios obtidos pela aplicação pouco informada ou desassistida de seu instrumental teórico comprometem não apenas os resultados em pesquisa, mas a própria evolução da semiótica enquanto ciência geral dos processos sígnicos ou semiose. Os esforços para reverter este quadro estiveram tradicionalmente concentrados na 


\section{Infodesıgn}

produção de manuais introdutórios e avançados de semiótica geral e aplicada (e.g. Coelho Neto, 1980; Deely, 1982; Eco, 1976; Nöth, 1990, 1995; Santaella, 1983, 1995, 2002; etc.). Apenas

recentemente, aliando o amadurecimento das discussões em torno das teorias de base da semiótica às possibilidades hipermidiáticas de ensino à distância, aprendizado interativo e engenharia semiótica, foram desenvolvidos os primeiros protótipos digitais de diagramas semióticos interativos: 10cubes@ e 3N3@ (@ 2001 Farias, Queiroz \& Gomes). Na esteira destes aplicativos, SignType - Tipificador Semiótico Assistido para Dados Fenomenológicos - propõe-se como um software facilitador e didático na tarefa de classificação e análise semiótica de extração peirceana de qualquer espécie de objeto ou evento.

Os dois principais objetivos deste aplicativo são: (1) capacitação científica de pesquisadores e estudiosos de quaisquer áreas do conhecimento na metodologia de classificação semiótica de extração peirciana baseada em 10 tipos 3-tricotômicos de signo; e (2) processamento de input fenomenológico (baseado em descrições impressionísticas) em output semiótico (baseado na lógica triádica que rege o conceito de signo de Peirce) com otimização do aproveitamento, por parte do usuário, do potencial científico da semiótica, principalmente no que diz respeito à compreensão do processo de funcionamento dos 10 tipos de signo como um espaço dinâmico de relações coordenadas (Queiroz, 1997, p. 57) e suas conseqüências epistemológicas.

Este projeto se enquadra dentro da proposta de "engenharia homem-signo" de Zellweger (1982) ou, em sua versão mais atual, sign design (Farias \& Queiroz, 2000). A metodologia proposta para sign design, especificada por Queiroz (2002, pp. 105-109, 124), compreende quatro fases: (i) conceitualização, (ii) desenvolvimento, (iii) experimentação e (iv) avaliação dos resultados. O projeto encontra-se, atualmente, na fase (ii).

O desenvolvimento de um aplicativo como este envolve não apenas questões computacionais (a programação propriamente dita) e de design de interface (a viabilização da interação humanocomputador), mas também questões específicas de design da informação. Transformar conceitos e processos teóricos complexos em modelos gráficos compreensíveis e plenamente utilizáveis é uma tarefa bastante difícil.

Após uma breve descrição das principais conclusões obtidas na primeira fase deste projeto, será feita a descrição do estágio atual de desenvolvimento, destacando-se as principais características e questões pertinentes ao design da informação do SignType. Questões semióticas, computacionais e educacionais serão abordadas apenas na medida em que necessárias para a compreensão dos objetivos do design da informação.

\section{Conceitualização}

A etapa de conceitualização do aplicativo foi, até agora, a mais longa. Através dela foram definidos o conceito do aplicativo, seus objetivos, a metodologia de aplicação da semiótica de Peirce que está subjacente ao seu funcionamento e as etapas (ações) que ele deve permitir. O mais amplo espectro de funcionamento (em número de ações) do aplicativo deverá ser em número de 5:

1. Avaliação e descrição, em termos semióticos, do input fenomenológico;

2. Seleção dos aspectos sígnicos mais relevantes (levantamento aspectual);

3. Qualificação dos aspectos em tipos de signo viáveis;

4. Classificação dos tipos viáveis segundo critério de afinidade à descrição fenomenológica;

5. Diagramação das relações coordenadas entre os tipos finais obtidos (output);

Uma sexta etapa poderá ainda ser proposta: o mapeamento da semiose possível entre vários signos classificados. A complexidade teórica e computacional envolvida (cf. Gomes, Gudwin \& Queiroz, 2003), entretanto, mantém esta etapa em suspenso até que possa ser resgatada.

O cerne conceitual do aplicativo está contido nas etapas 2, 3 e 4; sem elas não há SignType. Quanto à metodologia de classificação semiótica empregada nestas etapas, há um diferencial fundamental: ela se apóia nos tipos mais comuns de erro e/ou subaproveitamento comumente efetuados por pesquisadores pouco versados no assunto (Pauluk, 2003, p. 147 passim) para refinar o resultado obtido ao final do processo classificatório.

Ao permitir que o usuário faça um levantamento prévio dos aspectos específicos do fenômeno analisado reportando-se às três tricotomias que dão origem aos dez tipos finais de signo (CP 2.233-264) sem aplicar nenhuma das regras geradoras destes dez tipos (cf. Queiroz, 
1997, 2002), o aplicativo pode ampliar o resultado final apresentando algumas das classes impossíveis determinadas pelo usuário como sendo, na verdade, aspectos semióticos relevantes

do fenômeno analisado que normalmente ficariam sem qualquer destaque nos diagramas tradicionalmente utilizados para modelar as relações entre as 10 classes. Esta metodologia foi aplicada experimentalmente e com sucesso em arqueologia pré-histórica (Pauluk, 2002), na crítica da classificação de grafismos rupestres proposta por Anati (1994).

A etapa número 1, ainda que prevista, não está conceitualmente definida. Pretende-se que venha a trabalhar com grupos associativos descritivos de termos que possam ser escolhidos (ou propostos) pelos usuários dentro das tricotomias de relação "signo-signo", "signo-objeto" e "signointerpretante", mas ainda há dúvidas da eficiência deste método.

A última etapa atual, de número 5 , compreende uma variedade de diagramas já existentes e que pretendem modelar as relações entre as 10 classes de signo de Peirce. 10cubes $\odot$ é um exemplo refinado deste tipo de diagrama, mas existem muitos outros (e.g. Walther-Bense, 2000, pp. 35-36; Merrell, 1991, p. 17; Balat, 1989-91, p. 86 apud Queiroz, 2002, p. 109; Marty s/d; etc.). Estes diagramas serão implementados computacionalmente, tornando-se interativos e integrados ao aplicativo como módulos.

SignType pretende, como foi visto, fazer com que pesquisadores de quaisquer áreas interessados na exploração experimental e aplicada da semiótica peirceana sejam capacitados teórica e metodologicamente em uma importante área desta disciplina simultaneamente ao processo de operação do aplicativo e obtenção de resultados qualitativamente superiores. mplícita em todas as etapas descritas anteriormente está, portanto, a possibilidade de se recorrer, conforme a necessidade, ao um menu de ajuda.

Diagramas digitais interativos como 10cubes $\odot$ e 3N3@ trabalham em um nível avançado de complexidade teórica. Apesar de contarem com um dispositivo de ajuda (Help), este se restringe a uma página explicativa das funções e atribuições dos ícones e mecanismos do aplicativo. Seu público-alvo é, portanto, restrito a especialistas da área. SignType, por sua vez, procura ampliar este número de usuários através da possibilidade de se trabalhar em um nível de complexidade teórica que vai do introdutório até o avançado; em vista desta ampla gama de usuários, o aplicativo deverá prever um assistente (Wizard) didático que auxiliará o usuário na utilização do software, na compreensão dos conceitos utilizados pelo programa e na interpretação e aplicabilidade dos resultados obtidos.

\section{Desenvolvimento}

Definida a parte conceitual, foi iniciado o trabalho de desenvolvimento do aplicativo. Computacionalmente, foi desenvolvida uma máquina de estados em linguagem $\mathrm{C}++\mathrm{com} \mathrm{o}$ objetivo de testar algumas funcionalidades da estratégia de levantamento aspectual. O software deverá ser desenvolvido com tecnologia Shockwave@ e Shockwave 3DC, independente de plataforma e passível de implementação na web (para uso on-line). A interface está sendo desenvolvida em Macromedia Flash MX@, enquanto toda a unificação do programa será feita através do Director@. Entretanto, questões mais específicas no que concerne à interface, ao wizard e à programação serão desenvolvidas em outra oportunidade.

Um outro diferencial deste software, portanto, será focado neste artigo: o uso de alguns conceitos de design da informação no processo de otimização do aproveitamento das capacidades heurística, elucidativa e crítica da semiótica pelo usuário. Estes conceitos podem ser descritos da seguinte maneira: (1) configurabilidade de visualização da informação; (2) alternabilidade de modelos gráficos; (3) comparabilidade entre etapas de processamentos concomitantes. Através da análise dos módulos correspondentes às etapas 2, 4 e 5 vistas na seção 2, cada uma destas características será definida e exemplificada.

\subsection{Configurabilidade de visualização da informação}

O módulo abaixo (figura 1a) corresponde à etapa de número 2, "seleção dos aspectos sígnicos mais relevantes" ou, simplesmente, levantamento aspectual. Neste módulo o usuário pode escolher um ou mais tipos sígnicos dentre as três tricotomias peirceanas que levam à geração das 10 classes de signos. Feita a seleção, aciona-se o comando "qualificar" e as restrições cenopitagóricas (CP 8.328) são aplicadas à seleção do usuário, e o resultado é mostrado em um novo módulo, correspondente à etapa de número 3 (observável apenas nas figuras $3 a$ e $3 b$ abaixo). 


\section{Infodesıgn}

Figura 1a: Módulo para levantamento aspectual

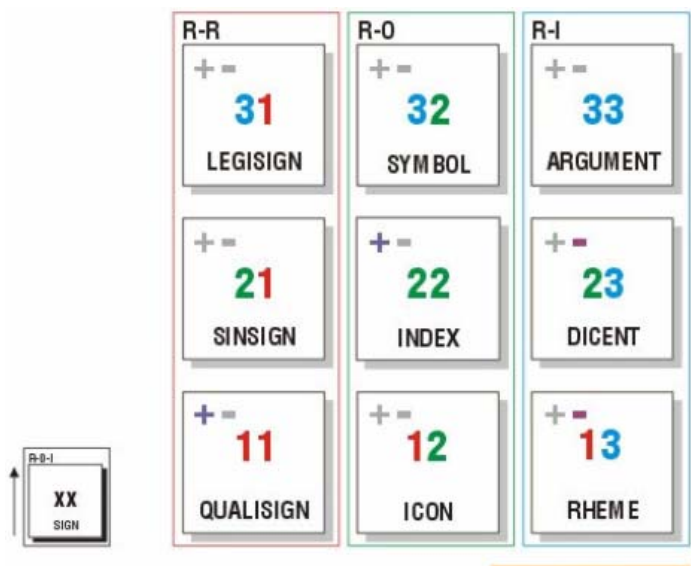

QUALIFY

O pequeno signo gráfico à esquerda funciona como comando de ativação e desativação dos elementos do módulo: ao clicar em qualquer um de seus elementos, este torna-se escuro e ativa o elemento correspondente no módulo. As separações em colunas, nas cores vermelho, verde e azul, indicam as 1a, 2a e 3a tricotomias de Peirce. Seguindo o mesmo formalismo para o uso de cores que Queiroz (2002, p. 110), o vermelho está sempre para a primeiridade assim como o verde para a secundidade e o azul para a terceiridade, as categorias universais de Peirce (CP 1.545- 567). Os signos gráficos de "+" e "-" correspondem, respectivamente, à seleção inclusiva (aspectos qualificados juntos) e exclusiva (aspectos qualificados separadamente) (Pauluk, 2002, p. 34).

Na configuração apresentada abaixo (figura 1b), estão desativadas as coordenadas que identificam as classes, bem como a demarcação das tricotomias. Mesmo que os nomes fossem também desativados, seria possível compreender a hierarquia das classes dentro do processo de qualificação através do uso de cores. O modelo de hierarquização é semelhante ao utilizado na cartografia (cf. Bertin, 1967, pp. 84-91) e se baseia, principalmente, na variação de tons de gris (value), mas também em variações graduais de matizes (buscando uma hue harmony), uma vez que a hierarquização atua simultaneamente na vertical e na horizontal, ou seja, entre as classes de uma tricotomia e entre as próprias tricotomias.

Figura 1b: Módulo para levantamento aspectual
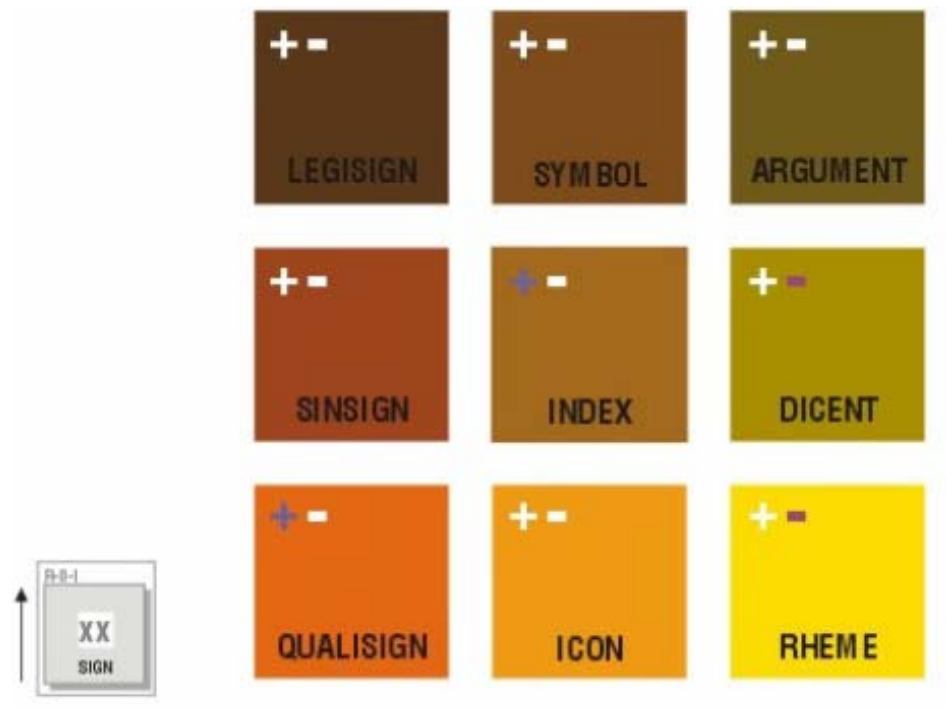

\section{QUALIFY}

Na figura 1c (abaixo), pode-se notar que a ordem das classes dentro de cada tricotomia foi 
invertida. A seta à esquerda do comando de ativação encontra-se agora voltada para baixo, indicando a inversão e a disposição das classes em sentido decrescente (de baixo para cima).

Figura 1c: Módulo para levantamento aspectual

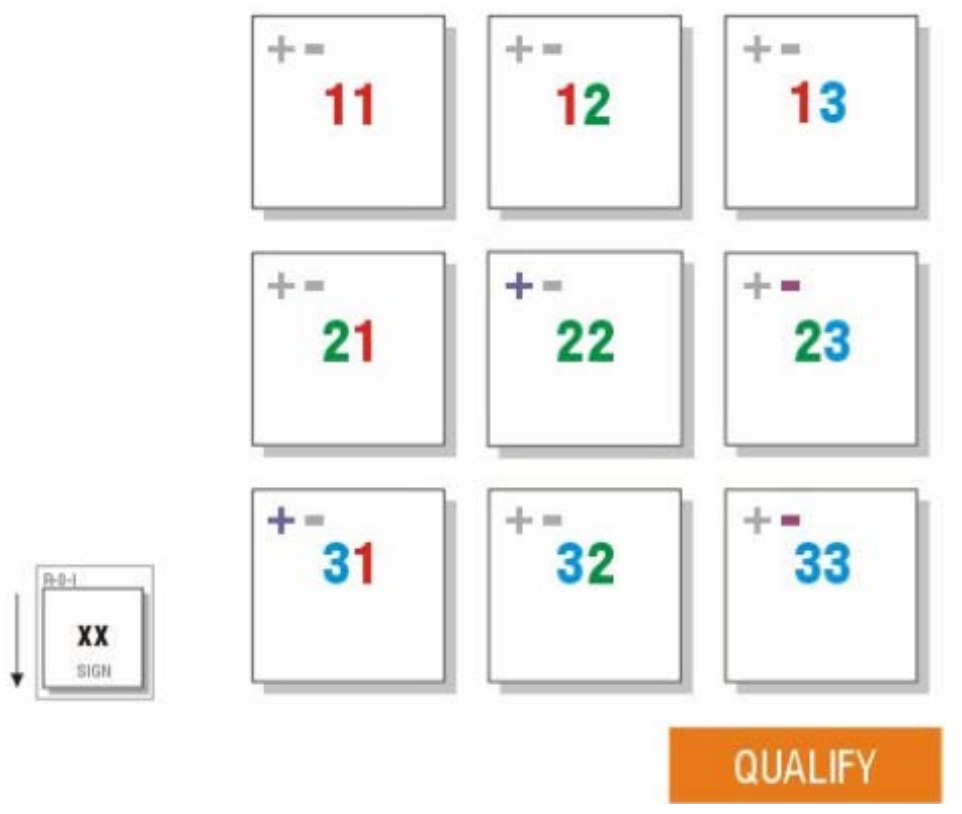

A importância desta possibilidade deve-se ao fato de que, comumente, a representação gráfica das três tricotomias de Peirce se dá em uma tabela (e.g. Nöth, 1995, p. 90; Coelho Netto, 1980, p. 62 etc.) como a que segue:

Tabela 1: Representação comum da classificação 3-tricotômica de Peirce

\begin{tabular}{l|lll} 
Tricotomia & \multicolumn{3}{l}{} \\
$\begin{array}{l}\text { Relação } \\
\text { Categoria }\end{array}$ & II IIno-signo & \multicolumn{1}{c}{ signo-objeto } & signo-interpretante \\
\hline Primeiridade & Quali-signo & Ícone & Rema \\
Secundidade & Sin-signo & Índice & Dicente \\
Terceiridade & Legi-signo & Símbolo & Argumento
\end{tabular}

A importância da configurabilidade da visualização da informação reside, portanto, no fato de que o usuário poderá:

- Escolher a representação à qual está mais habituado ou da qual consegue inferir a informação de maneira mais rápida e completa;

- Ocultar informações desnecessárias ou com as quais não se está trabalhando;

- Encontrar a melhor combinação de informações de acordo com a tarefa que está sendo executada;

\subsection{Alternabilidade de modelos gráficos}

O módulo abaixo (figura 2a) corresponde à etapa de número 4 "classificação dos tipos viáveis segundo critério de afinidade à descrição fenomenológica". As representações mais tradicionais da classificação em 10 tipos de signo baseiam-se modelos gráficos de Peirce (CP $2.264,8.376)$ e, ainda que sejam as únicas previstas para o SignType até o momento, outras representações estão sendo estudadas (e.g. Queiroz, 2002, p. 73; Merrell, 2000 etc.). Os nomes dos tipos de signos seguem o mesmo formalismo de cores referido em 3.1, e o negrito é usado para diferenciar a parte fundamental da parte redundante dos nomes das classes (cf. CP 2.264). O comando à esquerda no módulo permite, novamente, ativar e desativar elementos, assim como 


\section{Infodesıgn}

alternar entre os modelos gráficos utilizados. Ao clicar no comando laranja, à direita, o usuário parte para o módulo 5, de diagramação das relações entre as classes.

Figura 2a: Módulo para classificação dos tipos viáveis

\begin{tabular}{|c|c|c|c|c|c|c|c|}
\hline \multicolumn{2}{|c|}{$\begin{array}{l}\text { I } \\
\text { QUALISIGN } \\
\text { ICONIC } \\
\text { RHEMATIC }\end{array}$} & \multicolumn{2}{|c|}{$\begin{array}{c}\text { V } \\
\text { LEGISIGN } \\
\text { ICONIC } \\
\text { RHEMATIC }\end{array}$} & \multicolumn{2}{|c|}{$\begin{array}{c}\text { VIII } \\
\text { LEGISIGN } \\
\text { SYMBOLIC } \\
\text { RHEMATIC }\end{array}$} & \multicolumn{2}{|c|}{$\begin{array}{c}\mathbf{X} \\
\text { LEGISIGN } \\
\text { SYMBOLIC } \\
\text { ARGUMENTAL }\end{array}$} \\
\hline & \multicolumn{2}{|c|}{$\begin{array}{c}\text { II } \\
\text { SINSIGN } \\
\text { ICONIC } \\
\text { RHEMATIC }\end{array}$} & \multicolumn{2}{|c|}{$\begin{array}{c}\text { VI } \\
\text { LEGISIGN } \\
\text { INDEXICAL } \\
\text { RHEMATIC }\end{array}$} & \multicolumn{2}{|c|}{$\begin{array}{c}\text { IX } \\
\text { LEGISIGN } \\
\text { SYMBOLIC } \\
\text { DICENT }\end{array}$} & \\
\hline & & \multicolumn{2}{|c|}{$\begin{array}{c}\text { III } \\
\text { SINSIGN } \\
\text { INDEXICAL } \\
\text { RHEMATIC }\end{array}$} & \multicolumn{2}{|c|}{$\begin{array}{c}\text { VII } \\
\text { LEGISIGN } \\
\text { INDEXICAL } \\
\text { DICENT }\end{array}$} & & \\
\hline IYPE & & & \multicolumn{2}{|c|}{$\begin{array}{c}\text { IV } \\
\text { SINSIGN } \\
\text { INDEXICAL } \\
\text { DICENT }\end{array}$} & & & \\
\hline
\end{tabular}

\section{DRAW}

O modelo triangular mantém a ordem do modelo anterior, ainda que no original (CP 8.376) esta ordem esteja invertida horizontalmente. Pretende-se incluir a opção de inversão, como no módulo anterior, visto em 3.1. Novamente o que está em jogo aqui é a intimidade do usuário com determinadas representações, quando ele já as conhece, ou simplesmente sua preferência por determinados modelos gráficos.

Os tipos de signos selecionados, em ambos os modelos gráficos, aparecem contornados de laranja e destacados em amarelo. O primeiro nível de classes viáveis mas menos prováveis aparecem apenas contornadas de laranja, e o segundo nível de menos prováveis aparece contornada de amarelo (como pode ser visto nas figuras 3a e 3b). Infelizmente, os critérios que permitem a classificação de classes como mais ou menos prováveis não pode ser aprofundada aqui, mas não se trata de um cálculo probabilístico e sim da possibilidade de uma classe em incluir ou não os resultados da qualificação sem ultrapassar as regras de envolvimento ditadas pelas classes da última tricotomia (relação signo-interpretante).

Figura 2b: Módulo para classificação dos tipos viáveis

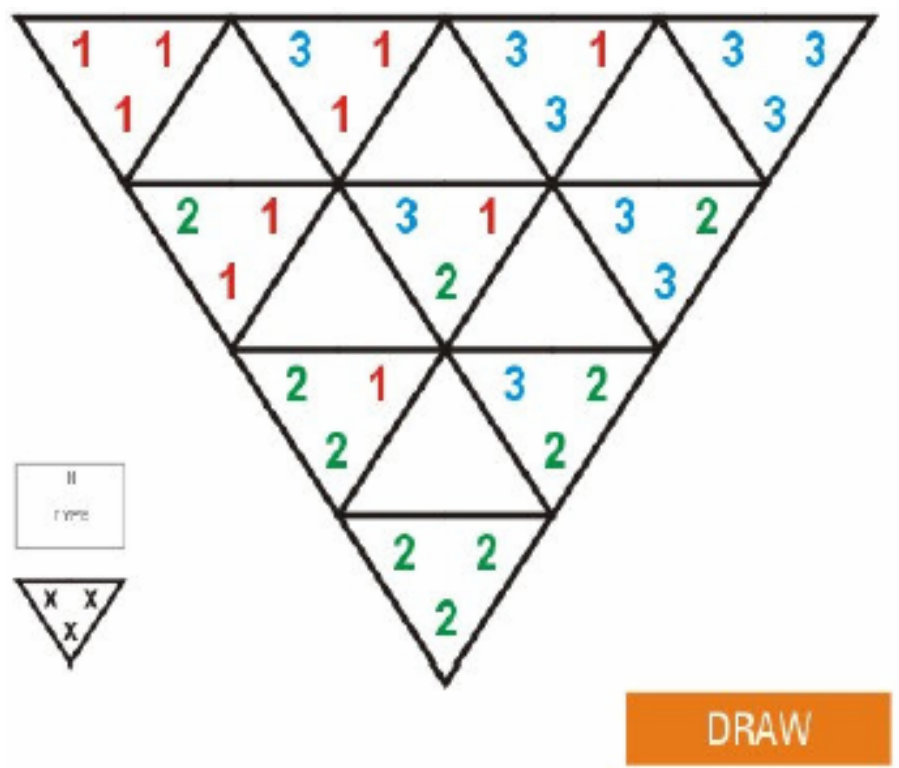

A figura 2c traz uma fusão de elementos característicos dos dois modelos. A hierarquização através de números romanos facilita o reconhecimento do padrão de ordenação, 
enquanto que os números coloridos permitem uma rápida identificação das classes sígnicas que constituem os tipos em questão.

Figura 2c: Módulo para classificação dos tipos viáveis

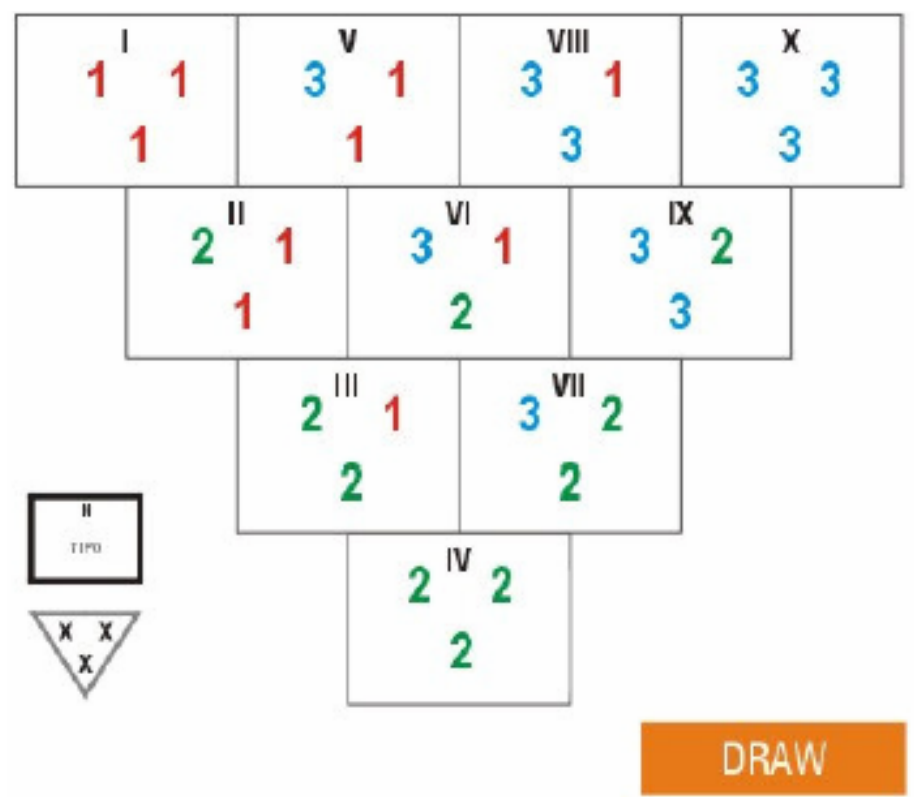

Resumindo: para o usuário do SignType, a importância da alternabilidade de modelos gráficos encontra-se em:

- Permitir a escolha de modelos aos quais se está acostumado ou mais adequados ao que se pretende;

- Viabilizar a alternância entre modelos sem haver alternância da informação;

- Conhecer diferentes modelos e, conseqüentemente, diferentes maneiras de se representar graficamente um mesmo conceito ou processo;

\subsection{Comparabilidade entre etapas de processamentos concomitantes}

A figura abaixo (3a) é uma versão preliminar de como funcionará a interface do SignType. O aplicativo, após inicializado, traz apenas o menu superior de controle, sem qualquer módulo aberto. Não há ordem pré-definida para o uso dos módulos; cada módulo, no entanto, prevê uma tecla de ação ("qualificar", "classificar", "diagramar", etc.) que define o módulo seguinte a ser usado. Por exemplo, ao realizar-se uma classificação e se clicar em diagramar, o módulo aberto é o último.

Os módulos podem ser deslocados dentro da interface do SignType, ou mesmo minimizados. Será possível rodar vários módulos iguais simultaneamente, permitindo a resolução de tarefas paralelas ou mesmo da análise simultânea de hipóteses relacionadas. O último módulo, "diagramação das relações coordenadas entre os tipos finais obtidos", aparece sempre em tamanho maior, uma vez que prevê gráficos de maior complexidade. O gráfico que aparece abaixo é uma variação simplificada de Marty (s/d), utilizado apenas para fins ilustrativos. O signo gráfico que aparece dentro deste módulo, no canto inferior direito, permite a diminuição do tamanho do módulo para $1 / 4$ de seu tamanho original, de forma a poder comparar os resultados em até quatro diagramas simultaneamente.

Os diagramas previstos para o módulo final são provenientes de diferentes épocas e fontes. Diagramas digitais interativos, como 10 cubes $\odot$, precisam de não mais que uma adaptação de linguagem computacional. Gráficos como os de Marty (ibidem), que já comportam o uso de cores, serão adaptados de forma a tornarem-se dinâmicos (animados) e interativos. Gráficos estáticos em $\mathrm{P} \& \mathrm{~B}$ poderão ser convertidos em modelos dinâmicos e interativos conforme a viabilidade desta transformação. 


\section{Infodesıgn}

Figura 3a: Interface do SignType. Módulo para diagramação das relações coordenadas entre classes

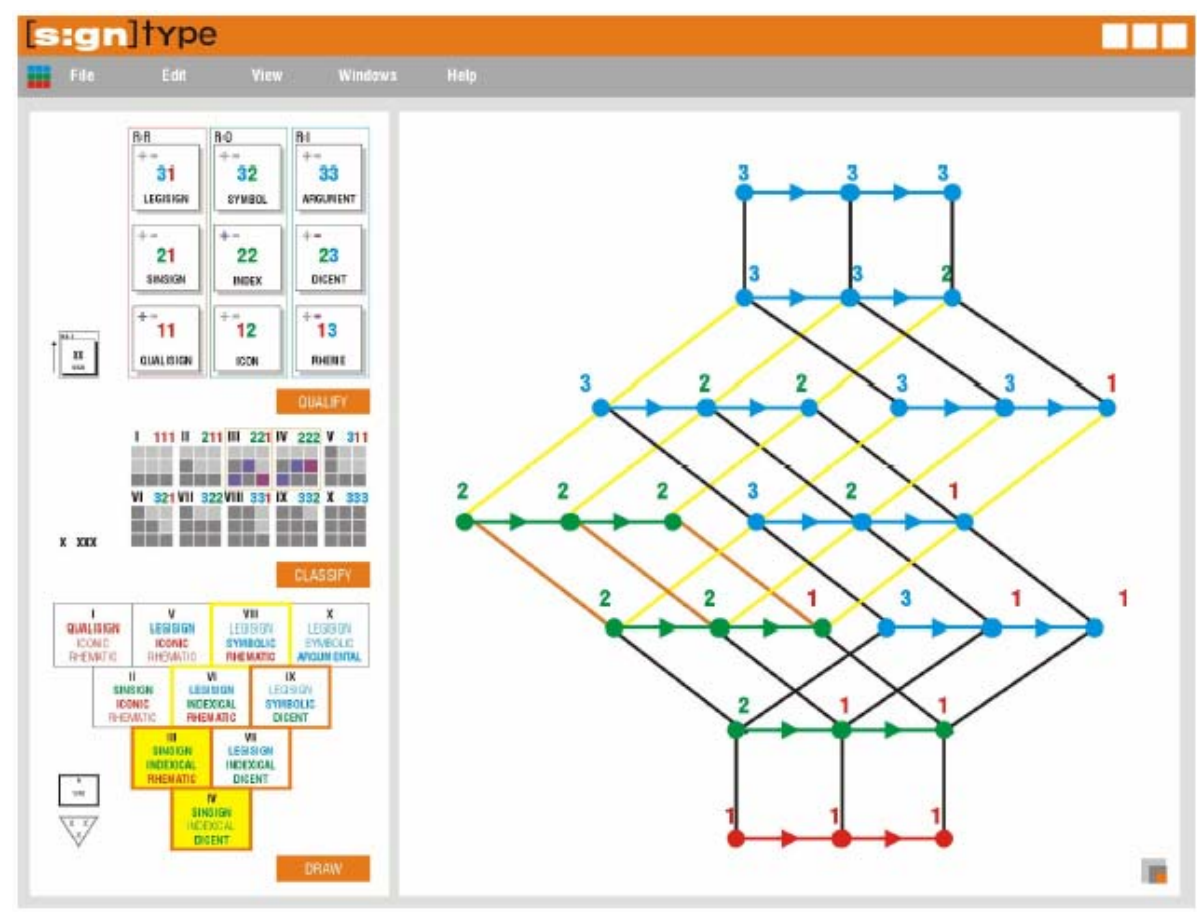

Apesar de vinculados, alterações em um dos módulos não devem surtir efeito em seu subseqüente até que seja clicada a tecla de ação. Cada módulo deverá prever uma pequena barra superior que permita sua identificação e a do nome da seção que está desenvolvendo. Se o usuário, por exemplo, está desenvolvendo duas hipóteses de levantamento aspectual em seções paralelas, ambas com o objetivo de estabelecer a melhor classificação semiótica do efeito de morphing em animação digital, ambas as seções poderão correr sob os nomes de "morph1" e "morph2", e nos módulos se leria "Levantamento aspectual - morph1", "Qualificação - morph1" etc.

Quanto maior o número de módulos abertos, mais espaço seria requisitado da área de trabalho do monitor, até que se torne necessário o uso de barras de rolagem ou sobreposição de módulos em cascata. De qualquer modo, a função a ser ressaltada é que todo e qualquer modo pode ser comparado, tanto com um similar desenvolvendo uma seção paralela, como com um módulo diferente desenvolvendo a mesma seção ou uma seção paralela.

Figura 3b: Interface do SignType. Módulos para diagramação em comparação 


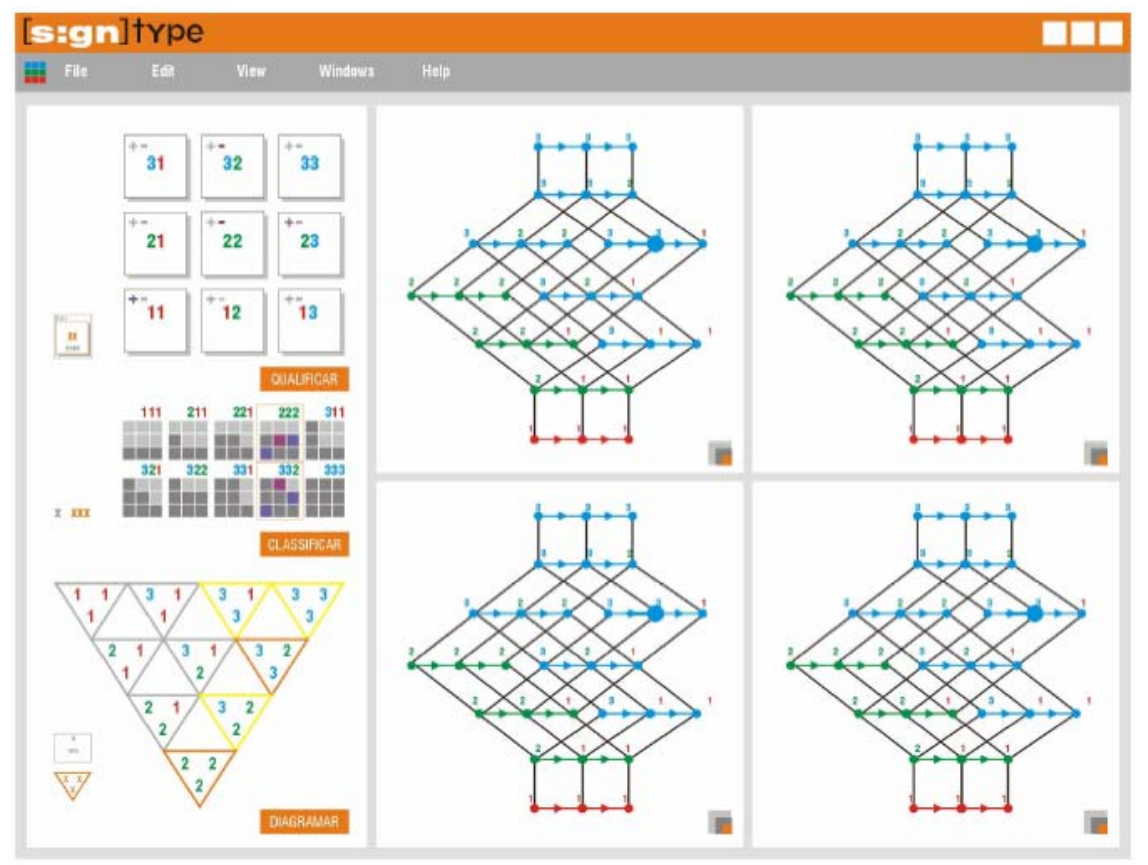

A importância da comparabilidade entre etapas de processamentos concomitantes é evidente em outras interfaces: em jogos, por exemplo. Saber o quanto de "energia" ainda possui o opositor, quais são suas qualidades e estratégias, qual sua estrutura, ou seja, poder comparar o desempenho de dois jogadores simultaneamente é o mesmo que poder avaliar duas hipóteses ao mesmo tempo.

\section{Conclusões}

O modelo de DiBiase do processo de conhecimento visual explicitado por MacEachren (1994, p. 2) ressalta a importância das etapas de exploração e confirmação visual (idem, pp. 3-6) na esfera privada descrita como pensamento visual. Todas as características do design da informação do aplicativo SignType buscam priorizar estas etapas, sendo o próprio aplicativo compreendido como um recurso heurístico e crítico para o pensamento visual sobre processos semióticos.

Configurabilidade, alternabilidade e comparabilidade de e entre modelos gráficos são recursos independentes de design da informação, mas que contêm em comum, a qualidade de permitir ao usuário diferentes pontos de vistas sobre a mesma informação, enriquecendo os resultados ao final do processo.

\section{Agradecimento}

Somos gratos ao apoio de Rangel Jungles e Alexandre Lin, recém incorporados à equipe. O projeto SignType recebeu apoio financeiro do CNPq (403569/2003-6).

\section{Referências}

Bertin, J. (1967) 1983. Semiology of graphics. Diagrams, networks, maps. London: The University of Wisconsin Press.

Coelho Netto, J. T. (1980). Semiótica, informação e comunicação: diagrama da teoria do signo. São Paulo: Perspectiva.

Deely, J. (1982) 1990. Semiótica básica. São Paulo: Ática.

Eco, U. (1976) 1997. Tratado geral de semiótica. São Paulo: Perspectiva.

Farias, Priscila. (2000). Sign design: semiótica aplicada ao design e design aplicado à semiótica. In: P\&D Design 2000 - $4^{\circ}$ Congresso Brasileiro de Pesquisa e Desenvolvimento em Design, 2000, Novo Hamburgo. Anais do P\&D Design 2000. Rio de Janeiro: AEnD-BR / Estudos em Design. v. 2. p. 1047-1054 


\section{Infodesıgn}

Farias, P. \& Queiroz, J. (2000). Notes for a dynamic diagram of Charles Peirce's classifications of signs. In Semiotica 131. 1/2, 19-44.

. (2003). On diagrams for Peirce s 10, 28, and 66 classes of signs. In Semiotica147. 1/4, 165-184.

Gomes, A., Gudwin, R. \& Queiroz, J. (2003). Towards meaning processes in computers from Peircean semiotics. In: SEED - Semiotics, Evolution, Energy, and Development. 2003(2): 69-79, disponível em http://www.library.utoronto.ca/see

Marty, R. (s/d). Le vrai treillis des classes des signes triadiques. Disponível em http://www.univperp.fr/see/rch/lts/marty/vrai-treillis.htm, acessada em 10/01/2005.

Merrell, F. (2000). Peirce's basic classes of signs in a somewhat different vein. In J. Queiroz (Ed.). Digital Encyclopedia of C. S. Peirce, disponível em www.digitalpeirce.org.

MacEachren, A. (1994). Some truth with maps: a primer on symbolization and design. Washington: Association of American Geographers

Nöth, Winfried. (1990). Handbook of semiotics. Bloomington: Indiana Univ. Press. . (1995) 1998. Panorama da semiótica: de Platão a Peirce. São Paulo: Annablume.

Pauluk, M. (2002). Distinções analíticas e hipóteses classificatórias da tipologia dos signos da 'arte rupestre' de Anati a partir da semiótica de Peirce. Monografia apresentada como requisito parcial para obtenção do título de Mestre, PUC-SP.

. (2003). Sistemas de escrita: Abordagens, tipologias, perspectivas em semiótica. Dissertação de Mestrado, PUC-SP.

Peirce, C. S. (1866-1913). 1994. The Collected Papers of Charles Sanders Peirce. Electronic edition of vol. I-VI [C. Hartshorne, \& P. Weiss (eds.), Cambridge: Harvard University, 1931- 1935], vols. VII-VIII [A. W. Burks (ed.), Cambridge: Harvard University, 1958]. Charlottesville: Intelex Corporation. [Citado como CP, número à esquerda do ponto indica volume, números à direita indicam parágrafos.]

Queiroz, J. (1997). Sobre as 10 classes de signos de C.S. Peirce. Dissertação de Mestrado, PUCSP

. (2002). Modelos das relações sígnicas na semiose segundo C. S. Peirce: evidências empírico-teóricas. Tese de Doutorado, PUC-SP.

Santaella, Lucia. (1983) 1987. O que é semiótica. São Paulo: Brasiliense. . (1995) 2000. Teoria geral dos signos: como as linguagens significam as coisas. São Paulo: Pioneira.

. (2002). Semiótica aplicada. São Paulo: Thompson.

Zellweger, S. (1982). Sign-creation and man sign engineering. In Semiotica 38, 1/2, 17-54.

\section{Sobre os autores}

Marcel P. Pauluk é mestre em Comunicação e Semiótica pela PUC-SP, professor do DDesignUFPR, vice-líder do Grupo de Pesquisa \& Desenvolvimento em Design e pesquisador associado ao Núcleo de Design \& Sustentabilidade e ao Laboratório de Animação Interativa. Desenvolve pesquisas em semiótica, design da informação e design gráfico sustentável.

André L. Battaiola é pós-doutor pela Universidade de Wisconsin (EUA), professor do DDesignUFPR, membro do Grupo de Pesquisa \& Desenvolvimento em Design e coordenador do LAl Laboratório de Animação Interativa, implementado com auxílio do CNPq. Pesquisa o desenvolvimento de jogos de computador educacionais. 